\title{
Chlorothiazide Sodium
}

National Cancer Institute

\section{Source}

National Cancer Institute. Chlorothiazide Sodium. NCI Thesaurus. Code C65319.

The sodium salt form of chlorothiazide, a short-acting, benzothiadiazinesulfonamide derivative belonging to the class of thiazide diuretics. Chlorothiazide is excreted unchanged by the kidneys. 